\title{
Representación de los indígenas en las leyes generales de educación de Colombia
}

Representation of Indigenous People in the General Laws of Education in Colombia
Representação

dos povos indígenas

nas leis gerais de

educação da Colômbia
Segundo semestre de 2020 - pp. 71-86 Segunda época

N.
Javier Guerrero Rivera* https://orcid.org/0000-0001-5928-1087

Sandra Soler Castillo** https://orcid.org/0000-0003-3155-5642

\section{Para citar este artículo}

Guerrero Rivera, J. y Soler Castillo, S. (2020). Representación de los indígenas en las leyes generales de educación de Colombia. Folios, (52). https://doi.org/10.17227/folios.52-9559

* Doctor en Educación. Docente de la Universidad Libre, Bogotá, Colombia.

Correo electrónico: javiguer66@hotmail.com

Artículo aprobado

$03 \cdot 02 \cdot 2019$

** Doctora en Lingüística y Comunicación. Docente del Doctorado Interinstitucional en Educación Universidad Distrital Franciso José de Caldas, Bogotá, Colombia.

Correo electrónico: stsolerc@udistrital.edu.co. 


\section{Resumen}

Este artículo de investigación explora la relación entre educación, discurso legal y racismo. Desde los estudios críticos del discurso, se analizan las tres leyes generales de educación de Colombia y los textos jurídicos y políticos que las sustentan, con el objetivo de develar las estructuras y estrategias discursivas empleadas para representar a los indígenas a lo largo del periodo comprendido entre 1870 y 1994. Se argumenta que ha habido una invisibilización en la representación de los indígenas como actores sociales del país y que cuando se han representado ha sido como sujetos carentes: salvajes, incivilizados e incluso inhumanos. El ideal de educación que trazan las tres leyes se presenta como una opción homogeneizadora que busca, mediante acciones como reducir, evangelizar o civilizar, sacarlos de la deficitaria condición en que se encuentran y conducirlos por la senda del desarrollo y el progreso social, económico y cultural, argumentos presentados como ideales comunes.

\section{Palabras clave}

Educación; discurso legal; estructuras discursivas; estrategias discursivas; racismo

\section{Abstract}

This research paper explores the relationship among education, legal discourse, and racism. From the Critical Discourse Analysis perspective, the authors analyze the three general laws of education in Colombia, and the juridical and political texts that support them. This analysis aims at revealing the discursive structures and strategies used to represent the indigenous people between 1870 and 1994. The authors argue that there has been an attempt to invisibilize the representation of indigenous people as social actors in the country. Moreover, when represented, they have been portrayed as uncivilized, savage, dispossessed individuals, and even inhuman. The ideal of education that the three laws outline is presented as a homogenizing option that seeks, through actions such as reducing, evangelizing or civilizing, to get them out of the deficient condition in which they find themselves and lead them on the path of development and social, economic and cultural progress,

arguments presented as common ideals.

\section{Keywords}

Legal discourse; education; racism; representation of actors and actions

\section{Resumo}

Este artigo de pesquisa explora a relação entre educação, discurso jurídico e racismo. A partir dos estudos críticos do discurso, são analisadas as três leis gerais de educação da Colômbia e os textos legais e políticos que os apóiam, com o objetivo de revelar as estruturas e estratégias discursivas utilizadas para representar os indígenas ao longo do período entre 1870 e 1994. Argumenta-se que houve uma invisibilidade na representação dos povos indígenas como atores sociais no país e que, quando representados, tem sido como sujeitos carentes: selvagens, incivilizados e até desumanos. 0 ideal de educação delineado pelas três leis é apresentado como uma opção homogeneizadora que busca, por meio de ações como redução, evangelização ou civilização, tirá-los da condição deficiente em que se encontram e conduzi-los no caminho do desenvolvimento e do progresso social, econômico e cultural, argumentos apresentados como ideais comuns.

\section{Palavras chave}

Educação; discurso jurídico; estruturas discursivas; estratégias discursivas; racismo 


\section{Introducción}

Tras más de cinco siglos de conquista y colonización, y de luchas de los pueblos indígenas de Colombia por garantizar sus derechos, su situación en la actualidad poco ha cambiado. El exterminio físico y cultural, la pobreza, la exclusión educativa, la representación negativa de los medios de comunicación y el discurso cotidiano, el poco interés de la academia en abordar los temas étnicos y la escasa o débil legislación para proteger a estas comunidades continúan siendo una constante.

El extermino histórico por el racismo, la discriminación y la intolerancia ha llevado a que de los 102 pueblos indígenas que aún quedan en Colombia, 32 cuenten con menos de 500 miembros que además habitan en las regiones más despobladas, pobres e “improductivas" del país (onIC, 2010). Los pueblos indígenas de Colombia son también la población más afectada por la distribución inequitativa de los recursos, es decir, la pobreza. En términos educativos, tal como lo indican documentos oficiales trasnacionales, como la Conferencia de Durban (Organización de las Naciones Unidas, ONU, 2001) y el Segundo Decenio Internacional de los Pueblos Indígenas del Mundo (onU, 2004), la exclusión y discriminación de los pueblos indígenas del mundo por el sistema educativo mayoritario, "ha sido también un mecanismo para la transformación impuesta y a veces la destrucción de las culturas indígenas" (ONU, 2005 , pp. 7-8). Por otra parte, la academia latinoamericana, en general, y la colombiana en particular, solo a partir de la década de 1990, especialmente desde la enunciación de la Constitución Política de Colombia de 1991, ha hecho suya la preocupación por estudiar la discriminación y el racismo. Sumado a esto, desde el discurso cotidiano, en Colombia nadie se considera racista, así a diario se produzcan o reproduzcan chistes o comentarios burlescos hacia las mal denominadas "minorías étnicas" (Soler, 2012; Van Dijk, 2003).

Frente al tema que aquí nos ocupa, la legislación colombiana, es relevante señalar que a la fecha no existen leyes efectivas que combatan las prácticas discriminatorias y racistas. Ello obedece, justamente, al gran argumento de su negación. Se ve como sospechoso, extraño y risible que alguien plantee el fenómeno como una práctica consuetudinaria en las élites, los medios de comunicación, los políticos, ciertos sectores de académicos, la escuela y la sociedad en general. En este sentido, también las leyes se convierten en un reflejo de esta situación por cuanto canalizan las experiencias culturales y sociales de los pueblos, legitimándolas, reformándolas y prohibiéndolas en una constante interdependencia y dialecticidad.

Teniendo en cuenta lo anterior, se puede afirmar que estudiar el discurso legal, ${ }^{1}$ en general, y el de las leyes generales de educación, en particular, es de gran relevancia para comprender el fenómeno del racismo, por cuanto constituyen la institucionalidad, toda vez que son la ley. Toda ley depende de las relaciones entre individuos, es decir, entre quienes las hacen en nombre de un grupo de poder (congresistas) y quienes no están en la misma condición, los Otros, en general. Ellas regulan las relaciones entre los individuos y delinean su devenir como grupo, colectividad o nación. En consecuencia, las leyes por su condición de generalidad (para todos los casos) e hipótesis (prescriben una conducta y amenazan con una sanción), dan "a los hombres la certeza del derecho, es decir, en hacerles saber lo que deben hacer o no hacer y a qué consecuencias se exponen haciendo o no haciendo" (Carnelutti, 2010, p. 55).

Este artículo tiene por objetivo general analizar e interpretar las estructuras y estrategias discursivas mediante las cuales las leyes generales de educación colombiana representan las alteridades indígenas y su implicación en el proyecto educativo nacional a lo largo de los dos siglos de vida republicana. Y los objetivos específicos buscan determinar las formas de nombrar y caracterizar a los indígenas, analizar las acciones o roles que se les atribuyen y, a partir de allí, develar por medio de qué argumentos y esquemas de argumentación personas o grupos sociales

1 El discurso lega/se entiende como aquel que ha sido construido por los legisladores (parlamentarios) y concretado en el texto de la ley como resultado final, sin que medie la aplicación e interpretación por parte de un juez en un tribunal; en este caso, se está hablando de discurso jurídico. 
específicos justifican y legitiman la exclusión, la discriminación y el racismo.

\section{Marco conceptual}

Para lograr estos fines, se emplea el análisis crítico del discurso (ACD) como perspectiva teórica y metodológica, de carácter inter- y transdisciplinario, especialmente en la perspectiva histórica planteada por Ruth Wodak $(2003,2013,2015)$ de la escuela de Viena, aunque también se emplearán algunos planteamientos de Teun van $\operatorname{Dijk}(2005,2007,2008)$, uno de los estudiosos más serios de la relación entre discurso y racismo.

El ACD considera el discurso como una práctica social que produce y reproduce desiguales relaciones de poder, en las que el abuso de poder conduce a la dominación de unos grupos sociales - las élites - sobre otros. En este sentido, el ACD se convierte en una posibilidad analítica e interpretativa de los fenómenos sociales, puesto que a través de los diversos usos del lenguaje se naturalizan y legitiman prácticas como la discriminación y el racismo. El ACD se ocupa de "analizar, ya sean éstas opacas o transparentes, las relaciones de dominación, discriminación, poder y control, tal como se manifiestan a través del lenguaje" (Wodak, 2003, p. 19).

El analista del discurso se enfrenta, para la comprensión de los fenómenos sociales, a tres momentos metodológicos en el proceso: en un primer momento está el hallazgo de las estrategias del discurso que pueden encubrir la discriminación, el racismo, la demagogia y la manipulación; o aquellas que están expresadas de manera evidente o transparente, pero que la mayoría de las veces se encuentran encubiertas o veladas en los discursos. La identificación de estrategias permite determinar y valorar diversas condiciones y características del fenómeno estudiado para luego entrar directamente al proceso de interpretación, en el que se apela a teorías y explicaciones provenientes de las ciencias sociales y humanas para comprender el fenómeno estudiado; $y$, en el momento final, surge la búsqueda de soluciones sociales y políticas a la problemática en cuestión (Wodak, 2003, 2013).
Uno de los tipos de discurso que mayoritariamente contribuye a la generación de representaciones y realidades sociales es el discurso jurídico de tipo normativo (legislativo ${ }^{2}$ ), en la medida en que las leyes son normas o preceptos que regulan los comportamientos humanos, por lo cual son expresión y construcción de la realidad; son las que crean el sentido de derecho como forma recta de actuar (Pardo, 1996). Se trata de discursos con un alto poder performativo, que como señala Bourdieu:

Es el extremo hacia el que pretenden todos los enunciados performativos, bendiciones, maldiciones, órdenes, votos o insultos; es decir, la palabra divina, la palabra de derecho divino que, como intuitus originarius que Kant atribuía a Dios y contrariamente a los enunciados derivados o comprobativos, simples registros de un dato prexistente, dan existencia a aquello que enuncian. (1985, p. 45).

Así, se entiende que toda ley "ordena" las acciones de los hombres; impone mandatos que no necesariamente son aceptados por los afectados o destinatarios; obliga a hacer, a obedecer y a someterse. En consecuencia, el incumplirlas ocasiona una sanción social o legal.

Las leyes generales de educación, como leyes superiores a todas las otras del mismo ramo o carácter, subsanan los vacíos y carencias de las vigentes en el momento de su promulgación. Su carácter general no se debe a su aplicabilidad, puesto que esta es una característica que es inherente a todas, sino por su trascendencia en amplitud y profundidad. Una ley general es una ley hito, en la medida en que fija y delimita un aspecto trascendental en un campo de control y de la vida social, y lo fija como uno de los componentes decisivos en el marco de un proyecto, en este caso, en el de nación colombiana. De este modo, es una ley/acontecimiento o hecho trascendental que señala la dirección, los límites y el devenir, en el caso que incumbe aquí, de la educación. Las leyes generales de educación se enuncian para instaurar un orden, unos ideales, un modelo de

2 Para abordar la diferencia entre los distintos tipos de discurso jurídico, véase Álvarez (2008). 
educación y, en consecuencia, un modelo de hombre, de ciudadano, y de identidad individual, social y nacional. En esta vía, ellas encarnarían, entonces, una capacidad transformadora de la educación, el ideal de saldar la deuda histórica con los excluidos y los millones de pobres, proyectando una capacidad esperanzadora para el conjunto de la sociedad.

En esta lógica, el estudio de la discriminación y del racismo a partir de las leyes reviste un gran interés por tratarse de un discurso preceptivo, establecido arbitrariamente para regular los comportamientos de una colectividad. Más aún, cobra relevancia - en este caso particular- por ser el discurso de las leyes generales de educación el que proyecta la escenificación en la escuela de una pedagogía, unos valores, determinados conocimientos y métodos, ciertas acciones, relaciones y sensibilidades; es decir, proyectan un tipo de sujeto para la nación.

\section{Marco metodológico}

\section{Enfoque}

Esta investigación sigue, como ya se mencionó, el aparataje teórico y metodológico de los estudios críticos del discurso. Procede analíticamente 1) recopilando e integrando el conocimiento disponible de carácter histórico, social y político en el que se inserta el fenómeno discursivo estudiado; 2) estableciendo las estructuras discursivas que se utilizan para discriminar étnica o racialmente a las personas, y 3) relacionando las estructuras discursivas con estrategias discursivas, entendidas, siguiendo a Wodak, como "un plan de prácticas más o menos intencional (incluyendo las prácticas discursivas) que se adopta con el fin de alcanzar un determinado objetivo social, político, psicológico o lingüístico" (2003, p. 115).

\section{Procedimiento}

Estas formas sistemáticas de estructurar el lenguaje se localizan en planos de organización y complejidad diferentes, que incluyen: 1) estrategias de nominación o modos de nombrar a los actores sociales, como formas de categorización de la pertenencia, uso de nombres propios, colectivización, gentilicios, sinécdoques y metáforas, entre otras;
2) estrategias de predicación, entendidas como las valoraciones positivas o negativas de los actores sociales y las acciones que realizan, y 3 ) estrategias argumentativas, o maneras de justificar las atribuciones de nominación y predicación que justifican la discriminación y el racismo. Y responden a las preguntas: 1) ¿Cómo se nombra a las personas?, 2) ¿Qué rasgos, características, cualidades o acciones se les atribuyen?, y 3) ¿Mediante qué argumentos se justifica o legitima la exclusión, discriminación, eliminación o explotación de otros?

\section{Corpus}

El corpus está constituido por las tres leyes generales de educación de Colombia, a saber: el Decreto Orgánico de Instrucción Pública de 1870; la Ley 39 de 1903 o Ley Orgánica de Educación; y la Ley 115 de 1994 o Ley General de Educación, vigente. Es importante señalar que cada una de ellas fue enunciada en el marco de una Constitución Política Nacional: 1863, 1886 y 1991, respectivamente, por lo cual (en algunos casos ineludiblemente) estas se consideran para el análisis. Dado que la Ley 39 de 1903 no desarrolla todos los aspectos concernientes al campo de la educación, tal como lo hacen las demás, se toma con el Decreto 491 de 1904 que la complementa.

\section{Análisis}

A continuación, se presentan algunos resultados del análisis en el que se da cuenta de los objetivos de la investigación. Para su discusión, se toman por separado la representación de actores y la representación de acciones, y en ambos casos se discuten las ideas o argumentos que sustentan o legitiman dicha representación.

\section{Representación de actores sociales y maneras de legitimarla}

Las tres Constituciones nacionales (1863, 1886 y 1991) y las tres leyes generales de educación (1870, $1903 / 1904$ y 1991) derivadas de aquellas poseen una manera muy particular de nombrar las alteridades indígenas, lo que, a su vez, establece un tipo particular de interlocución. 
La Ley de 1870 invisibiliza totalmente las alteridades indígenas. Desde el punto de vista discursivo, el hecho de no nombrar los sujetos o actores sociales es una estrategia que se emplea para negarlos, excluirlos y, aun, justificar y legitimar su extinción. Se recurre mayoritariamente a una estrategia de invisibilización, que consiste en:

[...] la práctica sistemática de excluir de los textos a determinados actores sociales y sus acciones. Los autores evitan incluir los grupos étnicos en condiciones comparables a los demás grupos, en cuanto a su representatividad en calidad de agentes históricos y sociales del país. (Soler, 2009, p. 238).

En las otras leyes objeto de análisis sí aparecen representadas las alteridades indígenas, pero de manera negativa. En el preámbulo a la Ley 089 de 1890 se señala: "Por la cual se determina la manera cómo deben ser gobernados los salvajes que vayan reduciéndose a la vida civilizada”. Esta primera nominación como salvaje es recurrente a través de las leyes y en ella se emplea una estrategia de inferiorización, en la que el otro se nombra como sujeto carente, al cual le faltan determinados rasgos para poder alcanzar el estatus de los sujetos representados como ideales o como norma; se trata de la ausencia de características ontológicas, epistémicas o praxiológicas. Esta forma de nombrar las alteridades indígenas también se observa en la Ley de 1903: "El Gobierno tomará especial interés, de acuerdo con los respectivos jefes de misiones, en atender a la evangelización e instrucción de las tribus salvajes" (LGE de 1903/1904, artículo 10).

Las leyes también recurren a la minorización del otro, en la que, al igual que en la estrategia anterior, se presupone una carencia: "Los indígenas serán asimilados por la presente Ley a la condición de los menores de edad, para el manejo de sus porciones en los resguardos" (Ley 089 de 1890, artículo 40). En este caso se duda de sus capacidades cognitivas para gobernarse a sí mismos.

Las leyes, en general, establecen una oposición entre sujetos salvajes y civilizados. Los primeros progresivamente deben ir reduciéndose en su condición para alcanzar mediante la educación el fin teleológico: la civilización. De manera expresa, así lo enuncia la ley de 1890 :

El Gobierno con la autoridad eclesiástica podrá delegar a los Misioneros facultades extraordinarias para ejercer autoridad civil, penal y judicial sobre los catecúmenos, respecto de los cuales se suspende la acción de las leyes nacionales hasta que, saliendo del estado salvaje, estén en capacidad de ser gobernados por ellas. (Ley 089 de 1890, artículo 2).

En la segunda ley general, la de 1903/1904, se los nombra únicamente en el artículo 10, siguiendo la misma línea:

Serán de cargo del Tesoro Nacional los gastos de la instrucción primaria de los Territorios Nacionales y los de catequización de indígenas, lo mismo que la provisión de textos de enseñanza, útiles de escritorio, etc., para las escuelas normales y primarias. El Gobierno tomará especial interés, de acuerdo con los respectivos Jefes de Misiones, en atender a la evangelización e instrucción de las tribus salvajes.

En esta representación, los sustantivos salvajes, indígenas y tribus salvajes adquieren un nivel de sinonimia. La colectivización inicial adquiere después un desarrollo al atribuírsele las características de tribus salvajes. Este es un indicio fundamental para comprender las relaciones entre las élites enunciadoras de las leyes y las alteridades indígenas.

Asimismo, en el Decreto 491 de 1904, que reglamenta la Ley General de 1903, se dedica un capítulo a estos grupos, denominado "Catequización de indígenas" (que se desarrolla en los artículos 29, 30, 31 y 32 ), en el cual se les denomina "tribus salvajes" [1], "indios" [2] e "indígenas" [2], con el mismo valor de sinonimia. Por otro lado, el artículo $10 \mathrm{da}$ cuenta del rol de las misiones, la evangelización y la instrucción/educación (civilización). Roles con sentido transparente en los enunciados, dado que no hay necesidad de ocultamiento pues la discriminación y el racismo se han naturalizado socialmente.

En la última ley general, la de 1994, las alteridades indígenas se nombran mediante la colectivización en formas compuestas que aluden a aspectos 
culturales y territoriales; aparece el adjetivo "étnico" en remplazo de "salvaje"; adjetivo en apariencia más neutro, pero que según la historia de discriminación y racismo puede cargarse negativamente en la comparación entre lo que se establece como "normal" y lo "étnico" o diferente, casi siempre de menor valor, reducido al folclor o al exotismo. Las frecuencias en esta ley incluyen: "comunidades indígenas" [2], "territorios indígenas" [2] y "grupos étnicos" [19]; esta última como una forma que comprende no solo a los pueblos indígenas, sino además a los afrodescendientes, indígenas y raizales (la ley omite a los gitanos o Rom). De esta manera, se lee en la Ley de 1994: "Se entiende por educación para grupos étnicos la que se ofrece a grupos o comunidades que integran la nacionalidad y que poseen una cultura, una lengua, unas tradiciones y unos fueros propios y autóctonos" (LGE de 1994, artículo 55). O “Fomentar el interés y el respeto por la identidad cultural de los grupos étnicos" (LGE de 1994, artículo 13, lit. $h$ ).

Así, el uso que se da va desde negar totalmente las alteridades, hasta usar indistintamente cualquiera de las cuatro denominaciones presentes en todas las leyes (tribus salvajes, indios, indígenas y grupos étnicos). En ese caso, ellas adquieren un nivel de equivalencia y sinonimia, lo cual explica las razones por las que, hasta en la actualidad, usar aparentemente la más "democrática", "apropiada” o "políticamente correcta" arrastra consigo un sentido peyorativo.

Esta manera de nombrar las alteridades indígenas deja ver que las constituciones y las leyes generales de la educación han sido enunciadas para unos interlocutores homogéneos, que pueden o no poseer bienes. Esta progresión económica y material abarca desde las élites hasta la gente del común (mestizos y campesinos). Los demás interlocutores, como las mujeres, los indígenas, los afrodescendientes, raizales y gitanos no cuentan, o solo lo hacen tangencialmente. Así, las leyes son un discurso legal construido y enunciado no para todos los habitantes del territorio colombiano, sino para una parte de la población. En la siguiente tabla se registra la manera de nombrar los actores en el corpus analizado.

Tabla 1. Maneras de nombrar a los indígenas en las tres constituciones y sus respectivas LGE

\begin{tabular}{|c|c|c|c|c|c|}
\hline Ley & F1: tribus salvajes & F2: indios & F3: indigenas & F4: grupos étnicos & F5: etnias \\
\hline C. P. N. 1863 & No & No & Sí (+tribus) & No & No \\
\hline LGE 1870 & No & No & No & No & No \\
\hline C. P. N. 1886 & No & No & No & No & No \\
\hline LGE 1903/1904 & Sí & $(\mathrm{Si})^{a}$ & Sí (Sí) & No & No \\
\hline C.P. N. 1991 & No & No & Sí & Sí & No \\
\hline LGE 1994 & No & No & Sí (+comunidades) & Sí & No \\
\hline
\end{tabular}

a La palabra entre paréntesis indica si se menciona en el Decreto 491 de 1904, que reglamenta la LGE de 1903. 
La muy baja frecuencia de uso de las formas para referirse a las alteridades indígenas o su exclusión total del discurso legal en las tres constituciones o en las tres LGE permite plantear algunas posibles explicaciones: 1) el legislador da por hecho que es natural excluirlas porque no existen; 2) pueden existir pero no son parte importante del país, no aportan al desarrollo; 3 ) existen pero no son parte fundamental de la identidad del "ser colombiano"; 4) su "condición y excepcionalidad" les obliga a asimilarse a la norma; y, 5) forman parte de la generalidad de receptores a quienes se dirigen las leyes, por lo tanto, la ley común o general es para ellas también, de manera que no amerita nombrarlas excepcionalmente.

Por último, es necesario resaltar dos aspectos importantes por tener en cuenta para el análisis y la interpretación de las tres LGE de Colombia, relacionados con los actores sociales beneficiarios de las leyes en cuestión y el efecto de las acciones del actor social Estado y sus operadores. En primer lugar, los actores sociales representados inicialmente en las leyes anteriores como "indios salvajes e incivilizados", sufren una transición que los vincula con "nuevas alteridades": "los mestizos", que en adelante se proyectarán en las leyes de la educación colombiana y continuarán la transformación por efecto de las acciones del Estado. La figura 1 muestra la transición de un estado a otro, su continuidad, especialmente por las acciones de la Escuela, es decir, el "Otro" como indio salvaje o bárbaro, por efectos de la gobernanza o reducción a la vida civilizada, va transitando a otros "estadios", siempre superiores: incipientes sociedades, catecúmenos, mestizos, comunidades indígenas, grupos étnicos o minorías, en razón de los efectos de la gobernanza, la reducción, la evangelización, la catequización, la instrucción, la vigilancia, la formación, el apoyo y la educación. Estas transformaciones, igualmente, sucederán a los sobrevivientes y a sus descendientes.

En segundo lugar, si la acción de gobernar ("como deben ser gobernados los salvajes") se vincula con "educar" ("atender a la evangelización e instrucción de las tribus salvajes"), en el sentido de dirigir, administrar y controlar a alguien bajo unos discursos y con unos dispositivos, esta acción se extiende igualmente a las tres LGE. En consecuencia, estas determinan la manera como se debe gobernar a los ciudadanos, para lo cual disponen de unos mecanismos y dispositivos operativos, epistemológicos, pedagógicos/didácticos e imponen unas acciones discursivas y sociales. Para cada una de las tres LGE se establecen los propios.

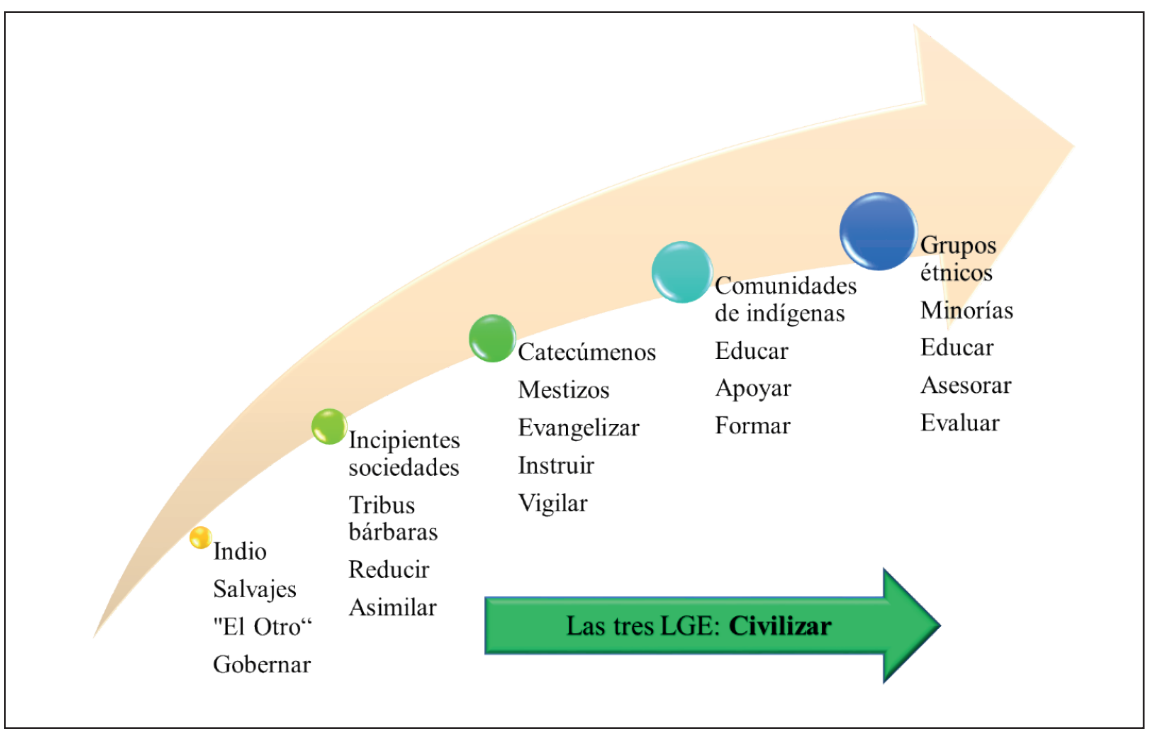

Figura 1. Transformación de los significantes de los actores sociales (alteridades) y las acciones. Fuente: elaboración propia. 
Para la LGE de 1870, por ejemplo, se impone el discurso liberal e ilustrado, el de la libertad, el progreso y las virtudes humanas, aplicable a una sociedad en estado de inmadurez y viciosa, como una clara necesidad de igualarse a las sociedades más civilizadas, para lo cual la educación se hace obligatoria y gratuita.

La LGE de 1903/1904, aunque presume un discurso distinto, mantiene muchos principios de la anterior, lo que se corrobora con la transcripción total o parcial de al menos 30 artículos; no obstante, impone un discurso confesional y conservador sobre la base de una sociedad en decadencia, con malestar y extraviada de todos los rumbos, para lo cual la educación es de carácter religioso y se encamina a la formación de obreros.

Finalmente, la LGE de 1994 despliega el discurso sobre los derechos humanos, las libertades, el multiculturalismo y la diferencia, para lo cual la educación fomenta los cambios para una sociedad que sigue en marcha buscando la democracia, el progreso y el desarrollo.

\section{Representación de acciones y maneras de legitimarlas}

A continuación, se presentan las acciones más generalizadas relacionadas con la acción de educar y los sentidos que va adquiriendo con el paso del tiempo en las diferentes leyes.

\section{La acción de evangelizar e instruir}

En el caso colombiano, las misiones religiosas se establecieron mediante el acuerdo de Concordato firmado entre el Gobierno colombiano y la Santa Sede el 31 de diciembre de 1887. Este se legalizó por medio de la Ley 35 de 1888 (27 de febrero) y es una obvia consecuencia de la recién aprobada Constitución de 1886 que designa al Dios cristiano como fuente suprema y a la religión católica, apostólica y romana como la única y universal que rige al país. Estas misiones eran cofradías, congregaciones o asociaciones religiosas que se asentaban en un lugar determinado, por lo general "inhóspito", concedido por el Estado colombiano.
Estaban conformadas por misioneros o religiosos, cuya tarea era "evangelizar" a los pueblos indígenas, es decir, "civilizarlos".

De manera específica, en relación con la evangelización/instrucción/adoctrinamiento (proyecto civilizatorio), se trata de un apoyo y cooperación "con preferencia al ejercicio de la caridad, a las misiones, a la educación de la juventud, a la enseñanza en general y otras obras de pública utilidad y beneficencia" (Concordato, 1887, artículo 11).

De esa forma, las misiones, como representantes de la religión católica, nombradas por la Santa Sede, desempeñaron un rol decisivo en toda la vida de la nación. Su misión fue la "civilización cristiana" (LGE de 1903, en Decreto 491 de 1904, artículo 32), que consistía en la evangelización e imposición de la fe y el dogma e, inherentemente, el discurso "civilizatorio y desarrollista" para establecer una nueva forma de pertenecer a, de identificarse con, de formar los valores, de enseñar el español, y de determinar los oficios y los roles; en síntesis, controlar y dominar a los indígenas en cuerpo y alma, en lo material y espiritual. De esto se trataba la occidentalización: la "reducción" de los pueblos indígenas para imponer los valores del eurocentrismo a los que aspira la joven nación colombiana, a saber: homogeneidad en la religión, el idioma, la ideología y la idea de sexualidad, los cuales se extenderán a todas las generaciones descendientes venideras.

Las misiones se desplazaban a los "territorios poco poblados" u "ocupados" por las "tribus salvajes". La población de estos territorios, por la distancia del centro político-administrativo (Santafé de Bogotá) o por haber permanecido sin la fe cristiana, se percibía en una condición más salvaje que otras del territorio, lo cual determinaba que permaneciera en caos y sin control. Así, eran estos tres aspectos: territorios "despoblados" y distantes, "tribus más salvajes", y caos y "sin control", los que justificaban la presencia misional y la consiguiente colonización/ civilización. Estos territorios en los que se llevaba a cabo la misión civilizatoria, se llamaron a partir de entonces Territorios Nacionales, los mismos que en la Constitución de 1863, artículo 78, se denominan 
"Territorios poco poblados, u ocupados por tribus indígenas", sobre los cuales se puede "fomentar colonizaciones y mejoras materiales", y en la Ley General de Educación de 1903, artículo 10, “Territorios Nacionales", los cuales tuvieron vigencia hasta la Constitución de 1991 con el nombre de Intendencias y Comisarías.

Este proyecto "mesiánico" quedó justificado - entre otros aspectos - por la "existencia" de los "territorios poco poblados" y la creación de los Territorios Nacionales por cuanto con ellos era posible establecer diferencias para dominar y controlar, además de obtener grandes ganancias de tipo económico y misional.

A través de distintos dispositivos e instrumentos, las misiones de la Santa Sede constituían un "orden social”, de carácter religioso católico, único, mejor, universal y justo, sin otra alternativa. Tal orden social buscaba la occidentalización de los colombianos, en general, y de los indígenas, en particular, para construir al nuevo ciudadano, moldear la identidad de la colombianidad. La reducción a la vida civilizada de los pueblos indígenas de Colombia es un proyecto que no tiene grandes diferencias en los gobiernos de turno, sean estos liberales o conservadores. En estas normas cambian las estrategias del discurso, las formas, la superficie, pero el sentido se mantiene; pueden cambiarse o encubrirse los métodos o medios, pero se apunta al mismo fin, todo medio justifica el fin civilizatorio; la reducción del salvaje a la vida civilizada.

Así, entonces, los discursos sobre la inclusión, la inserción a la 'sociedad nacional' o, inclusive hoy día, sobre la multiculturalidad/interculturalidad que circulan desde las élites o el establecimiento e, incluso, la academia, son meros anuncios, por cuanto lo que ha sucedido es una falsa vinculación, una falsa solución a los graves problemas ocasionados por el racismo histórico estructural del que han sido víctimas las alteridades indígenas, bajo el ideal europeo moderno e ilustrado de asimilar a las alteridades al canon de hombre blanco, cristiano, hispanoparlante, ilustrado, poseedor de bienes, heterosexual, trasplantado - con semejantes carac- terísticas- a las nacientes naciones, con arreglo al colonialismo interno de cada país (Gonzáles, 2006).

En esta medida, esta inclusión es más una asimilación/absorción, despojo y destrucción cultural de las costumbres y hábitos que dice defender la cultura hegemónica. Esta defensa se traduce de distintas maneras, por ejemplo, al indicar que:

Los programas regulares para la educación de las comunidades indígenas tendrán en cuenta su realidad antropológica y fomentarán la conservación y la divulgación de sus culturas autóctonas. El Estado asegurará la participación de las comunidades indígenas en los beneficios del desarrollo económico y social del país. (Decreto 88 de 1976, artículo 11).

En las leyes derivadas de la Constitución de 1991 se encuentra esa misma defensa y "actitud democrática", presente en la reiteración de enunciados como los siguientes: "en concertación con los pueblos indígenas", "en concertación con los grupos étnicos", "en concertación con las autoridades y organizaciones de los grupos étnicos", "en concertación con las autoridades de las entidades territoriales indígenas y de los grupos étnicos" (LGE de 1991, arts. 59, 62, 63, otros); y, en el caso de la Ley 1381 o Ley de Lenguas Nativas, el artículo 3, titulado "Principio de Concertación", como un componente fundamental para interpretar y desarrollar dicha norma. Concertación que no ha ido más allá del papel, pues los hechos y las estadísticas demuestran el crítico estado de los indígenas en Colombia, tras su casi total exterminio físico y cultural.

No obstante lo anterior, y frente a las críticas explícitas hechas por algunos sectores al papel de la religión católica, como el acaparamiento indebido de la educación, la lesión de la soberanía nacional por la presencia de profesores extranjeros, el aprovechamiento particular de los dineros oficiales, la ambición, la anulación de los "valores autóctonos" de los indígenas, entre otros, los religiosos consideran que su tarea educativa/civilizatoria, además de ser una obra propia e inherente a su condición, en el caso colombiano, es una solicitud de ayuda manifiesta que hace el Estado al no poder desempeñar y 
responder con sus obligaciones. Se trata, entonces, de un acto de misericordia y bondad, tal como se observa cuando se señala que "Desde 1902, por otro Convenio, los Prelados misioneros recibieron, no por propia iniciativa sino a petición del Gobierno Colombiano, el encargo de dirigir la educación en sus territorios, en razón de la dificultad del Gobierno para atender ese deber suyo" (Conferencia Episcopal, 1976).

\section{Acciones para gobernar y reducir a los salvajes}

Al no aplicárseles las normas generales de la República a las alteridades indígenas, sino las leyes que los particularizan o diferencian, se cae en contradicciones entre lo justificado y la realidad, en este caso, en cuanto a la identidad y la autonomía. De esta manera, en un principio, luego de la Constitución de 1886, como hito refundacional, se determina que "El Gobierno podrá modificar, por medio de decretos y reglamentos, el Derecho común para la reducción y régimen de las tribus bárbaras ó salvajes existentes en el territorio de la República, atendiendo á sus especiales costumbres y necesidades" (Ley 153 de 1887, artículo 318).

En primer lugar, el Gobierno nacional se toma todas las atribuciones/acciones para determinar/ inventar las alteridades, lo cual lo puede hacer mediante la modificación del "Derecho común". En segundo lugar, el "Derecho común" no aplica para las "tribus bárbaras o salvajes" existentes por cuanto no merecen esas leyes. Tercero, el 'Derecho particular' atiende a las "especiales costumbres y necesidades" de las "tribus bárbaras", pero se les niega la autonomía. Cuarto, la nueva norma del Gobierno tiene como receptor de sus acciones (objeto directo) a los "bárbaros", porque estos son incapaces de gobernarse. Y, quinto, el objetivo de la ley es "la reducción y régimen de las tribus bárbaras o salvajes existentes", conforme a su condición de inferioridad.

De esto se deriva, entonces, el rol determinador $y$ activo del Estado frente al pasivo de las alteridades y la diferenciación de las alteridades para incluirlas, pero con un transparente planteamiento racista y discriminatorio, situado en el marco de los binarismos en los cuales el nosotros está cargado positivamente y el ellos, negativamente. Del mismo modo, se usa el argumento cultural de la identidad "atendiendo á sus especiales costumbres y necesidades [...]". Este aspecto es una constante y se observa, por ejemplo, en una norma posterior (Decreto 88 de 1976, artículo 11), en la que se hace explícito al señalar que toda la etnoeducación debe partir de "su realidad antropológica". Se asiste así a los nuevos racismos que dejan atrás lo biológico tras el desmonte científico del concepto de raza en el cual se sustentaban para dar inicio a los nuevos racismos de corte cultural, en los que las costumbres y tradiciones se convierten en el problema: la nueva amenaza (Bauman, 2006; Mbembe, 2016).

Remarcar "su realidad antropológica" induce a pensar en el concepto tradicional de la antropología, según el cual hay culturas superiores e inferiores producto de sus dinámicas internas propias, casi naturales. Estas transitan por distintos estadios y, en esa medida, la cultura superior o mayoritaria, en este caso la "cultura nacional", acciona estrategias para tener en cuenta a las demás, estudiarlos y proveerles recursos y soluciones acordes con su condición. En consecuencia, el Estado ratifica su rol activo $y$, a través de la educación y sus nuevos discursos, se encamina, en este caso, a conservar, recuperar, fomentar y divulgar "la cultura autóctona" de estas alteridades. En esta línea, la cultura nacional se preocupa por "estudiar" sus costumbres relacionadas con el vestido, la alimentación, la interrelación, los mitos, las leyendas, las creencias, las expresiones culturales como danzas y artesanías, el cuidado de los hijos, "la economía" y demás conductas "racionales o irracionales".

Este tipo de preocupación por el "Otro", se traduce en el nuevo discurso moderno sofisticado como los enfoques del "multiculturalismo" y las prácticas de la "inclusión", en los cuales persiste la idea de que todo cuanto acontece a las alteridades indígenas - y por asociación a sus descendientes-, obedece a su carácter biológico, por ley natural e, incluso, divina y no como una construcción o invención social hecha por las culturas hegemónicas 
y sus élites, cuyos resultados son el racismo y la discriminación y sus efectos sobre dichas alteridades.

Ahora bien, hablar de "su realidad antropológica" y "sus costumbres autóctonas" al referirse a los indígenas (Decreto 88 de 1976, artículo 11), tal como se ha dicho antes, no es otra cosa que la enunciación sofisticada o el cambio de los significantes utilizados en 1887 cuando se habla de "sus especiales costumbres y necesidades" de "las tribus bárbaras o salvajes existentes" (Ley 153 de 1887, artículo 318). Se trata, entonces, de una transformación de los significantes para nombrar y caracterizar a las alteridades indígenas más que de los significados y consideraciones sobre el "otro" para acentuar la diferencia con el propósito de marcar, inferiorizar y excluir a dichas alteridades.

Posterior a la Ley 153 de 1887, se arguye que "en cuanto sea posible se conservarán en tales sociedades las costumbres de gobierno que hayan tenido los salvajes, pero siempre que no se opongan a la moral cristiana o a los principios que informan la Legislación de la República" (Decreto 74 de 1898, artículo 2). Obsérvese que se toma en cuenta el aspecto identitario vinculado con la "conservación de las costumbres de gobierno de los salvajes", lo cual se circunscribe doblemente con el uso de dos restrictivos: uno al comienzo del enunciado, "en cuanto sea posible" y otro al final, "pero siempre que no se opongam a la moral cristiana". Lo anterior devela la negación de la autonomía y la autodeterminación de las alteridades, que se fija a la hora de enunciar la ley; por el contrario, se nota la sujeción de todo su actuar social y político a la "Legislación de la República”. Lo anterior había quedado sellado plenamente desde la Ley 72 de 1892, sobre el establecimiento de las misiones, cuando el Gobierno les delega a los "Misioneros facultades extraordinarias para ejercer autoridad civil, penal y judicial sobre los catecúmenos" (Ley 72 de 1892, artículo 2).

En síntesis, lo anterior permite dar cuenta de la transición de la acción de gobernar o reducir a los "salvajes" a la de educar (o etnoeducar) a los "grupos étnicos" o a sus descendientes, pasando por la de asimilar, evangelizar, catequizar, instruir y sus conexas, como una forma transparente de identificar a estos actores sociales (receptores beneficiarios) con atributos ligados con el racismo y la discriminación.

Acciones que dan fin a la educación

La transformación discursiva de las leyes generales de educación y sus desarrollos se puede notar constantemente y de forma diáfana en relación con distintos aspectos. Dicha transformación se da en el campo de los significantes, pero no en el de los significados.

En relación con el progreso, el desarrollo y la prosperidad material, por ejemplo, en primer lugar, la secuencia inicia con el reconocimiento de una sociedad viciosa, pobre y subdesarrollada, aspectos propios de la LGE de 1870; en segundo lugar, se continúa con los planteamientos de la LGE de 1903/1904, por ejemplo, en uno de los fines primordiales de las misiones religiosas y sus jefes que era "el del fomento de la prosperidad material del territorio y de los indios en él establecidos [...]" y "difundir entre los indios las industrias más convenientes, asignándoles premios y recompensas que los estimulen eficazmente" (LGE de 1903, en Decreto 491 de 1904, artículo 32). Este segundo momento se extiende hacia adelante, en pleno siglo $\mathrm{xx}$, con el Decreto 88 de 1976, en el cual se indica que a través de la educación para las alteridades indígenas "El Estado asegurará la participación de las comunidades indígenas en los beneficios del desarrollo económico y social del país" (Decreto 88 de 1976, artículo 11).

Y, finalmente, se cierra la secuencia con todo el discurso de la LGE de 1994 con campos semánticos en torno a la misma ideología del desarrollo con el uso de sintagmas como: avance científico y tecnológico, mejoramiento de la cultura, alternativas de solución a los problemas y al progreso social y económico del país (LGE de 1994, artículo 5, numeral 9), desarrollo integral, la función social de la educación, planes de desarrollo, lo más avanzado, avanzar, sector productivo, función socialmente útil, dimensión práctica de los conocimientos teóricos, conocimiento práctico, la capacidad para utilizar el conocimiento teórico en la solución de problemas, 
desarrollo económico del país, entre otros, que dan cuenta de este "nuevo orden educativo". Este aspecto es abundante y fácilmente rastreable en todas las leyes, tal como se ha mostrado en otros apartados.

En todos los casos, sea en las tres LGE o en las normas específicas para las alteridades indígenas, se muestra como una constante el ideal desarrollista y productivista bajo los preceptos occidentales. Dicho ideal se convierte en un propósito fundamental que se debe impulsar desde todos los frentes, especialmente desde el educativo, apelando a todas las estra- tegias y tácticas conductistas, como la asignación de premios y recompensas para buscar la eficacia en la productividad y encontrar la anhelada prosperidad material. En este orden de ideas, se observa que, aunque cambien los significantes, se llega al mismo punto: conducir a todas las sociedades, especialmente a las alteridades indígenas y sus descendientes, a salir del subdesarrollo y avanzar hacia el desarrollo y el progreso como última instancia, tal como se observa en la figura 2.

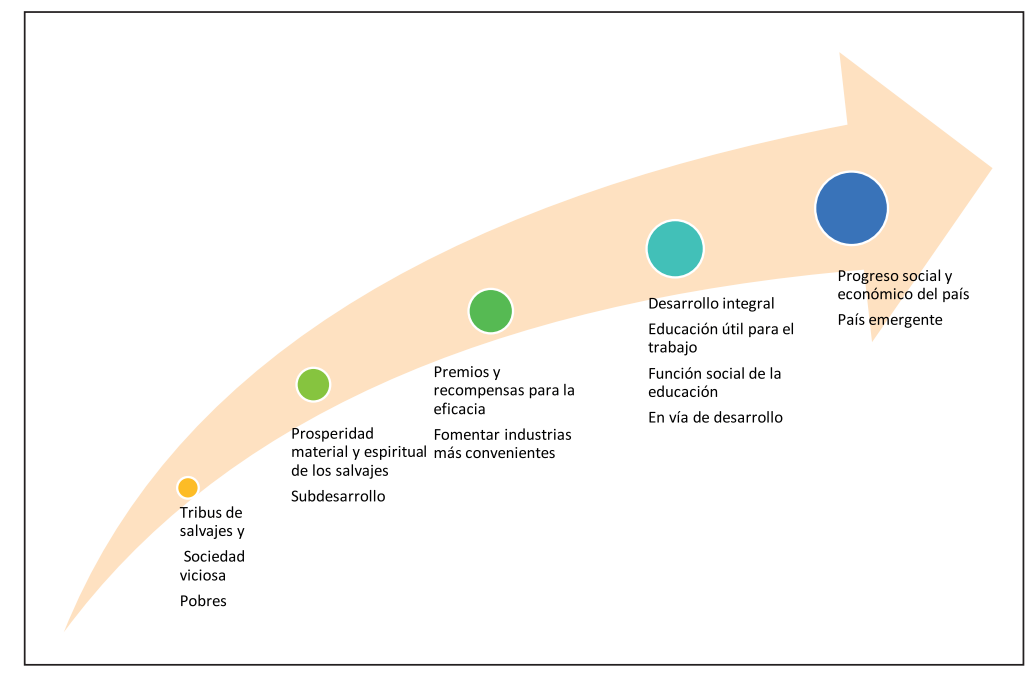

Figura 2. Secuencia de la transformación de los significantes sobre el "desarrollo" y la permanencia de su significado.

Fuente: elaboración propia.

La figura 2, por un lado, da cuenta de la variación discursiva ocasionada por el efecto de las diversas acciones educativas, desde "gobernar" y "reducir" hasta "etnoeducar", Por esta razón, situados en la LGE de 1870 y la LGE de 1903/1904, parte del actor social tribus de salvajes y de la sociedad viciosa en estado de pobreza, los cuales deben comenzar su proceso de prosperidad material y espiritual. Para superar esa condición, el actor social "Estado" fomenta las industrias más convenientes y los estimula con premios y recompensas para que prosigan hacia el desarrollo integral. En consecuencia, la educación debe ser útil y cumplir una función social de manera que transite hacia progreso social y económico del país, que prometen la LGE de 1994 y las leyes sobre la etnoeducación.
Por otro lado, el sentido ascendente de la figura, entendido como positivo, va de ser un país pobre, subdesarrollado, en vía de desarrollo y, actualmente, emergente, que se dirige quizá hacia un nivel de desarrollo superior o perfecto, incierto, distante por cuanto busca ser o parecer al impuesto por los imperios o por los centros de poder colonial. No obstante, ese ascenso positivo, que va de lo más básico o primitivo y salvaje hacia lo moderno y civilizado, sigue en el campo de lo negativo, en razón a que se desplaza en el escenario de la ausencia de prosperidad material o "subdesarrollo", está en el escenario de la línea abismal, del campo de los "Otros". 
Ahora bien, con respecto a los agentes y sus acciones relacionadas con el tema del desarrollo/ progreso, se pueden mostrar dos casos que ratifican el papel activo del Estado y la condición pasiva de las alteridades. En el primero, LGE de 1903, en el Decreto 491 de 1904, artículo 32, el sujeto que lleva a cabo la acción son "las Misiones", las cuales asumen la función o el rol "benefactor"/misional en favor de las nacionalidades indígenas, las cuales están en estado primitivo y salvaje. Por lo tanto, la meta para ellos es primaria, básica y diagnóstica; el que recibe la acción requiere de estímulos para asumir la conducta esperada.

En el segundo, Decreto 88 de 1976, el papel activo/asegurador ya no lo asume la Iglesia, sino el Estado; su rol proveedor/asegurador se dirige a unas naciones indígenas que requieren seguir hacia adelante, hacia el desarrollo y el progreso. El uso del verbo "asegurar" y los sustantivos "participación", "beneficios" y "desarrollo" devela, en apariencia, un papel más activo de las alteridades en su propio "desarrollo" y los consecuentes beneficios que explícitamente recaen sobre ellas. Así, la acción es directa, sin paliativos conductistas explícitos. Aunque estos usos discursivos suavicen el sentido, subyace la idea de alteridades subdesarrolladas, que necesitan transitar hacia el desarrollo, en un tránsito de lo "más negativo" hacia lo "menos negativo", pero, al fin y al cabo, negativo.

Lo anterior es equiparable con lo que anuncian la Constitución Política de 1991, la Ley General de Educación de 1994 y las subsiguientes leyes que norman sobre las alteridades indígenas, en relación con la identidad y la autonomía.

\section{Conclusiones}

A partir del análisis de las LGE se evidenció el uso de diversas estrategias discursivas y argumentativas que, por un lado, estructuran las leyes $y$, por otro, hacen del discurso legal o jurídico un dispositivo legítimo en sí, objetivo y universal, que a su vez legitima a los enunciadores y presenta como inobjetables sus intencionalidades expresadas en el entramado discursivo.
La representación de actores sociales en las leyes mostró como estrategias centrales la invisibilización, cuyo propósito es excluir lo diferente para unificar y homogeneizar una sola identidad con arreglo al proyecto de país, a la construcción de una identidad nacional, e implica dejar al margen las lenguas, las creencias, las prácticas culturales, las maneras de economía, las formas de organización y todo aquello que no se ajuste al nuevo ideal: una lengua, una religión, una ideología, un país monocultural. Y la representación negativa, al nombrarlos haciendo referencia a cualidades que evidencian supuestas carencias, como "indios", "tribus salvajes", "salvajes", o "minorías étnicas", que terminan por inferiorizar y minimizar a las alteridades indígenas.

En cuanto a las acciones, en la "legislación de tribus bárbaras", como en todas las leyes de la época que las nombran, la acción fundamental fue la "reducción de las tribus bárbaras" a la vida civilizada, mediante diversos dispositivos, especialmente el relacionado con las misiones católicas y su poder de acción sobre los pobladores del territorio. La acción principal es la evangelización, que los conduce al abandono de la condición salvaje e infiel, y permite incluso conmutar y rebajar las "penas corporales" una vez se catequice y bautice el reo. Todo el mecanismo tiene como fin último avanzar en la búsqueda de una identidad nacional homogénea, una suerte de "colombianidad".

En este sentido, las leyes muestran un único actor social con carácter activo, opuesto a las alteridades indígenas y sus descendientes, en quienes recae su actuar, confinándolas a un rol pasivo. La acción de "reducir", auténtica del Estado, las misiones y sus operarios, a través de los siglos, se convierte en la acción de "educar" y todas sus conexas, las cuales traspasan la legislación de la jurisdicción especial indígena y se instalan en las LGE para actuar sobre "los grupos étnicos" o "minorías" y los descendientes de aquellas "tribus bárbaras". Estas dos acciones han llevado a que se despoje, extermine y niegue la diferencia, a que se niegue la historia de las alteridades y sus aportes como pueblos en relación con el ser, poder, estar, pensar, sentir y su vínculo con la naturaleza, la vida y los demás. 
La legislación sobre las alteridades está pensada por las élites como un "deber ser" para gobernarlas, tutelarlas y dirigirlas por cuanto se parte del imaginario de que son entes incapaces de "vivir por ellos mismos", de poseer autonomía y autodirigir su devenir. Todo lo cual, en la realidad, en la escenificación de las normas ha llevado a que el racismo y la discriminación, manifiestos en el discurso, hayan determinado que históricamente tanto los indígenas como sus descendientes hayan sido despojados de sus tierras y recursos, de su condición humana, de sus valores culturales y de su identidad étnica, y que hayan sido incluso despojados de la vida misma (víctimas de la violencia, el genocidio, el holocausto indígena); en síntesis, un despojo de su condición ontológica, epistemológica y praxeológica, de la vida.

\section{Referencias}

Álvarez, G. (2008). La enseñanza del discurso jurídico oral y escrito en la carrera de abogacía. Revista sobre Enseñanza del Derecho, 6(11), 137-148. Recuperado de http://www.derecho.uba.ar/publicaciones/rev academia/revistas/11/la-ensenanza-del-discurso-juridico-oral-y-escrito-en-la-carrera-de-abogacia.pdf.

Bauman, Z. (2006). Comunidad. En busca de seguridad en un mundo hostil. Madrid: Siglo XxI.

Bourdieu, P. (1985). Qué significa hablar. Economía de los intercambios lingüísticos. Madrid: Akal.

Calvo Buezas, T. (1989). Los racistas son los otros. Gitanos, minorías y derechos humanos en los textos escolares. Madrid: Editorial Popular.

Carnelutti, F. (2010). Cómo nace el derecho. Bogotá: Temis.

Gonzáles, C. P. (2006). Sociología de la explotación. Buenos Aires: Clacso.

Mbembe, A. (2016). Crítica de la razón negra. Barcelona: NED.

Organización de las Naciones Unidas-onU. (2001). Conferencia Mundial Contra el Racismo, la Discriminación racial, la Xenofobia y las Formas Conexas de Intolerancia. Durban, Sudáfrica. Recuperado de http://www.un.org/es/events/ pastevents/cmcr/durban_sp.pdf.

Pardo, M. L. (1996). Derecho y lingüística. Cómo se juzga con palabras. Buenos Aires: Nueva Visión.
Soler, S. (2009). Racismo y discurso en los textos escolares. Representación de la diversidad étnica y racial en los textos de ciencias sociales en Colombia. En J. Arocha (ed.), Nina S. Friedemann: cronista de disidencias y resistencias (pp. 233-265). Bogotá: Universidad Nacional de Colombia ces.

Soler, S. (2012). Lengua, folclor y racismo. Estereotipos comunes sobre los grupos étnicos colombianos. En A. Castellanos y G. Landazury (comp.). Racismos $y$ otras formas de intolerancia de norte a sur en América Latina (pp. 125-148). México: Universidad Autónoma Metropolitana.

Van Dijk, T. (2003). Racismo y discurso de las élites. Barcelona: Gedisa.

Van Dijk, T. (Comp.) (2005). El discurso como interacción social. Barcelona: Gedisa.

Van Dijk, T. (Coord.) (2007). Racismo y discurso en América Latina. Barcelona: Gedisa.

Van Dijk, T. (Comp.) (2008). El discurso como estructura $y$ proceso. Barcelona: Gedisa.

Wodak. R. (2013). Critical Discourse analysis. En J. Ritchie, J. Lewis, C. M. Nicholls, y R. Ormston (eds.). Qualitative research practice: A guide for social science students and researchers (pp.185-202). London: Sage.

Wodak, R. y Meyer, M. (Comp.) (2003). Métodos de análisis crítico del discurso. Barcelona: Gedisa.

Wodak, R. y Reisigl, M. (2015). Discourse and racism. En D. Tannen, H. Hamilton y D. Schiffrin (Eds). The Handbook of discourse analysis (2. ${ }^{\mathrm{a} e d}$.) (pp. 576-596). India: Wiley- Blackwell.

\section{Fuentes primarias}

Conferencia Episcopal de Colombia (1976). Comunicado de la XXXII Asamblea Plenaria sobre Misiones, 13 de julio de 1976. Recuperado de https://www.cec. org.co/sites/default/files/web_cec/Documentos/ Asamblea-Plenaria/1976/Comunicado\%20sobre\%20 misiones\%20-\%201976.pdf

Congreso de Colombia. (25 de noviembre de 1890). Ley 089 de 1890, por la cual se determina la manera como deben ser gobernados los salvajes que vayan reduciéndose a la vida civilizada. Recuperado de http:// www.alcaldiabogota.gov.co/sisjur/normas/Norma1. $\mathrm{jsp} ? \mathrm{i}=4920$.

Congreso de Colombia. (26 de octubre de 1903). Ley 39 de 1903. Ley Orgánica de Instrucción Pública. 
Recuperado de http://www.mineducacion.gov. co/1621/articles-102524_archivo_pdf.pdf.

Congreso de Colombia. (8 de febrero de 1994). Ley 115 de 1994. Ley General de Educación. DoI: 41.214.

Constitución Política de los Estados Unidos de Colombia. (1863). Recuperado de http://www.banrepcultural. org/sites/default/files/brblaa1243262.pdf.

Constitución Política de Colombia. (1886). Recuperado de http://www.alcaldiabogota.gov.co/sisjur/normas/ Norma1.jsp?i=7153.

Constitución Política de Colombia. (1991). Recuperado de http://www.corteconstitucional.gov.co/inicio/ Constitucion\%20politica\%20de\%20Colombia\%20 -\%202015.pdf.

Corte Constitucional, Sala Segunda de Revisión. (26 de enero de 2009). Auto 004/09. M.P. Manuel José Cepeda Espinosa. Recuperado de http://www. corteconstitucional.gov.co/relatoria/autos/2009/ a004-09.htm.
Decreto Orgánico de Instrucción Pública Primaria. (1. ${ }^{\circ}$ de noviembre de 1870). Revista Colombiana de Educación, 5, Bogotá: UPN, CIUP.

Organización Indígena de Colombia (2010). En https:// www.onic.org.co/

República de Colombia y Santa Sede (1887). Concordato de 1887. Recuperado de https://www.cec.org.co/sites/ default/files/web_cec/Documentos/DocumentosHistoricos/1973\%20Concordato\%201887.pdf.

Vicepresidencia de la República. (3 de junio de 1904). Decreto 491 de 1904, por el cual se reglamenta la Ley 89 de 1903, sobre Instrucción Pública. Recuperado de http://www.mineducacion.gov.co/1621/articles-102515_archivo_pdf.pdf. 